\title{
Science for surgeons: Understanding pump thrombogenesis in continuous-flow left ventricular assist devices
}

\author{
Andreas R. de Biasi, MD, ${ }^{a}$ Keefe B. Manning, $\mathrm{PhD},{ }^{\mathrm{b}, \mathrm{c}}$ and Arash Salemi, $\mathrm{MD}^{\mathrm{a}}$
}

See related commentary on pages 673-4.

Left ventricular assist devices (LVADs) have emerged as a mainstay, lifesaving treatment option for patients with refractory heart failure, with 1 - and 2-year actuarial survival rates of $80 \%$ and $70 \%$, respectively, for the current generation of Food and Drug Administration-approved continuous-flow devices. ${ }^{1}$ Despite this progress, continuousflow LVADs are not without their shortcomings. One issue in particular continues to vex these devices and is increasingly garnering attention in the literature: Device thrombosis and its attendant thromboembolic complications.

After a recent article exposed an unexpected uptick in the incidence of pump thrombosis with 1 of the 2 approved durable continuous-flow pumps, ${ }^{2}$ a flurry of studies quickly ensued that sought to better delineate the problem of LVAD thrombogenesis. ${ }^{3-7}$ Much of this effort focuses on developing patient-level and/or device-specific predictors of thrombus formation as clotting is not inevitable with current devices. The results of such clinical endeavors will no doubt be vital to improving outcomes; however, what is often lost in these analyses is an understanding of the thrombus itself. Simple questions like, "What exactly is a thrombus?" are often taken for granted, yet, overcoming the multifactorial scourge of LVAD thrombosis demands that we understand the answers to these fundamental questions.

We therefore present a contemporary review of the basic science of thrombogenesis in the setting of LVAD support and begin by outlining how clots typically form in devices, incorporating new insights into established clotting cascades. Then, we invoke a Virchow's triad of sorts to explain the 3 fundamental determinants of pump thrombogenesis: (1) titanium's bioreactive surface acts as a nidus for

\footnotetext{
From the Department of Cardiothoracic Surgery, ${ }^{a}$ Weill Cornell Medical College, New York, NY; Department of Biomedical Engineering, ${ }^{\mathrm{b}}$ The Pennsylvania State University, University Park, Pa; and Department of Surgery, ${ }^{\mathrm{c}}$ Penn State College of Medicine, Hershey, Pa

Disclosures: Arash Salemi reports lecture fees from Edwards Lifesciences. All other authors have nothing to disclose with regard to commercial support.

Received for publication Oct 6, 2014; revisions received Oct 28, 2014; accepted for publication Nov 8, 2014; available ahead of print Dec 19, 2014.

Address for reprints: Arash Salemi, MD, Department of Cardiothoracic Surgery,

Weill Cornell Medical College, 525 E 68th St, M-404, New York, NY 10065

(E-mail: ars9001@med.cornell.edu).

J Thorac Cardiovasc Surg 2015;149:667-73

$0022-5223 / \$ 36.00$

Copyright (c) 2015 by The American Association for Thoracic Surgery

http://dx.doi.org/10.1016/j.jtcvs.2014.11.041
}

platelet aggregation; (2) LVAD-induced hypercoagulability is chiefly mediated by activated platelets (APs); and (3) aberrant flow predisposes to thrombogenesis via shearstress-induced platelet activation (SIPA), hemolysis, and stasis. In doing so, we explain how common clinical events can play out on a hemorheologic level to induce clotting. We close by reflecting on the implications of our enhanced understanding of pump thrombogenesis.

One must bear in mind that although the 3 factors we will discuss underpin many clinical mechanisms involved in clotting, they do not explain the problem in its entirety. This distinction is evidenced by the observation that the aforementioned increase in pump thrombosis appears to be dependent on implant era and by the fact that the problem seems to vary widely by center.

\section{DEVICE THROMBOGENESIS: A PLATELET PLUG AND A FIBRIN NETWORK}

The general scheme of device thrombogenesis is not unlike the hemostatic response to endothelial injury. Similar to arterial clots, device thrombi are largely plateletderived $^{8}$; pump thrombi begin forming when circulating APs attach to an adhesion protein (eg, von Willebrand factor [vWF] or fibrinogen) found on the blood-exposed surfaces of the titanium alloys used in LVADs (Figure 1). The platelets quickly start aggregating and, in turn, release numerous procoagulant proteins, including ADP and thromboxane $\mathrm{A}_{2}$ (these help activate and recruit other platelets and serve to propagate the thrombogenesis). ${ }^{9}$ As this self-perpetuating cycle of aggregation continues, the APs also begin binding to one another. Specifically, the glycoprotein fibrinogen forms crosslinks between GPIIb/IIIa receptors on neighboring platelets; the resultant conglomeration of interconnected platelets is analogous to the so-called platelet plug that is generated early during the hemostatic response to vessel injury. ${ }^{9}$

Almost simultaneous with these events, the local plasma concentrations of other coagulation proteins, particularly tissue factor (TF), start rising. ${ }^{9}$ Growing research has identified the source of much of this TF to be platelet-derived microparticles (MPs) ${ }^{10}$; these MPs have recently been implicated in pump thrombosis and may have utility as surrogate markers of platelet activation. ${ }^{11}$ The accumulating TF soon forms activated complexes with factor VIIa (through what is traditionally termed the extrinsic pathway); this leads to the activation of factors IX and $\mathrm{X}$ and then to the conversion of prothrombin to thrombin, the latter of which contributes to additional platelet activation. ${ }^{9}$ 


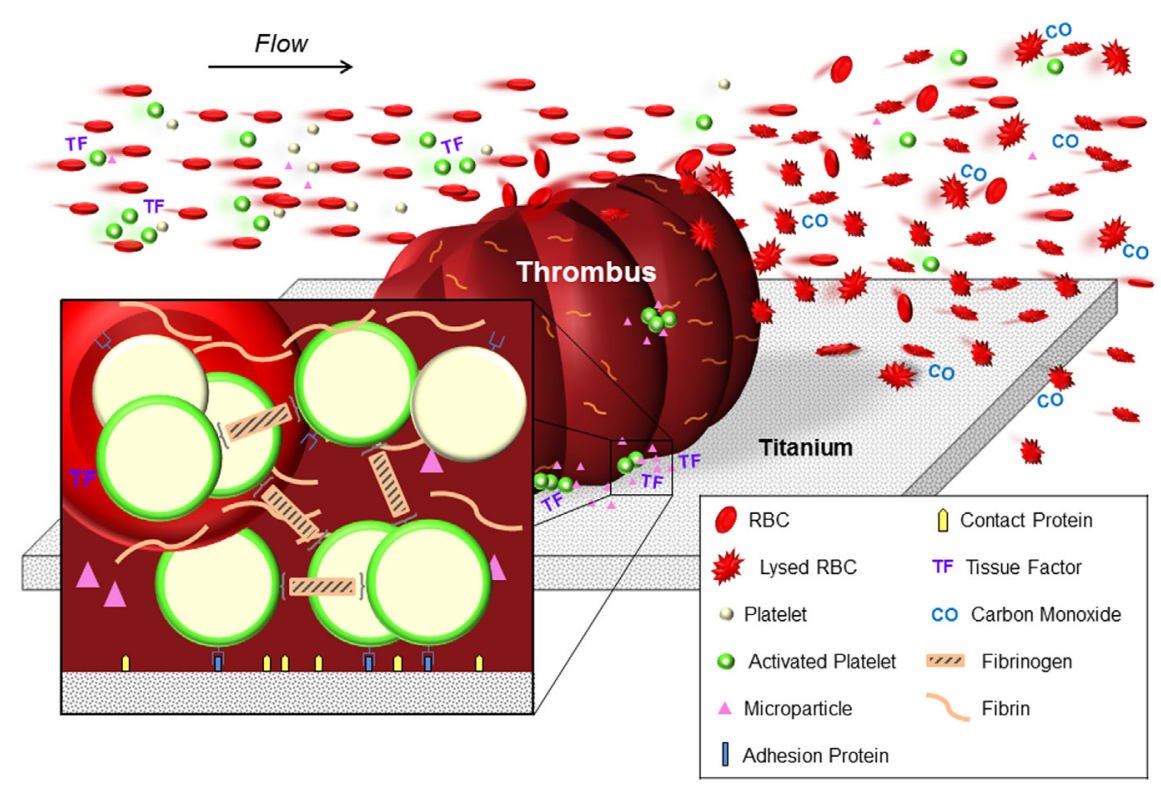

FIGURE 1. A growing pump thrombus. Shear-activated platelets adhere to various titanium-bound adhesion proteins, triggering the process of thrombogenesis. Platelet aggregation continues as neighboring activated platelets bind to each other via fibrinogen crosslinks. The release of microparticles from activated platelets increases local concentrations of procoagulant proteins, like tissue factor, that synergize with contact proteins to ultimately form a platelet-stabilizing fibrin network. The thrombus can ensnare passing erythrocytes that release carbon monoxide when lysed, further contributing to thrombus formation. $R B C$, Red blood cell.

Most notably, thrombin catalyzes the conversion of soluble fibrinogen into insoluble strands of fibrin-these strands create an interweaving fibrin network that ensnares passing erythrocytes and ultimately stabilizes the underlying platelet mass (Figure 1). ${ }^{9,12}$ Concurrently, so-called contact proteins (notably, high molecular weight kininogen [HMWK]), which are known to adhere to devices' titanium surfaces ${ }^{13}$ further promote the formation of thrombin and hence, fibrin, via the intrinsic pathway. ${ }^{9,12}$ The net result of these convergent coagulation cascades is the formation of the stabilizing fibrin network.

\section{FUNDAMENTAL DETERMINANTS OF PUMP THROMBOSIS: VIRCHOW'S TRIAD FOR DEVICES}

We have distilled the science governing pump thrombogenesis into more familiar terms - those of Virchow's triad. By way of analogy, the trio of endothelial injury, hypercoagulability, and stasis therefore becomes bioreactive material, APs, and aberrant flow, respectively, in the present context of LVAD support (Figure 2).

Although the goal of our review is to explain the basic science behind pump thrombosis, we would be remiss in not highlighting some of the key clinical contributors to device clotting as these incite the thrombogenic phenomena described herein (Table 1). A recently published review details these clinical risk factors and summarizes some of the progress our community has made thus far in lessening their contributions to thrombus formation. ${ }^{7}$ A complementary question to the issues addressed in that article serves as the backdrop to our next discussion: On the most biophysical, rheologic level, what governs device thrombogenesis?

\section{Bioreactive Material}

As in the response to endothelial injury, LVAD thrombosis begins with a specific nidus. Whereas the exposure of subendothelial collagen (to which platelets then attach) initiates typical vessel clotting, the analogous precipitant in LVADs can be found on the devices themselves. Titanium is the most biocompatible metal at our disposal when selecting materials to be used in assist devices. That being said, titanium alloys are not completely inert; even with appropriate systemic anticoagulation and antiplatelet therapy, titanium LVADs still have some inherent thrombogenic potential. ${ }^{3,4}$ This inescapable fact is explained by circulating platelet adhesion proteins, like fibrinogen, which (despite various surface treatments) manage to adhere to blood-exposed titanium. ${ }^{14}$

An article by Nielsen and colleagues ${ }^{13}$ outlines another contributor to titanium's bioreactivity: contact-proteinmediated coagulation. As mentioned earlier, the fibrin network that lends strength to a growing thrombus evolves in response to the actions of numerous prothrombotic contact proteins (eg, HMWK, factor XII, prekallikrein, and factor XI) that make up the intrinsic pathway. Similar to platelet adhesion proteins, these contact proteins can adhere to assist device surfaces (Figure 1 ). ${ }^{13}$ In so doing, contact proteins like HMWK set off a chain reaction that leads to abundant fibrin formation and additionally appear to contribute to the rate of clot growth. ${ }^{13}$ It has also been shown that this contact protein pathway can interfere 


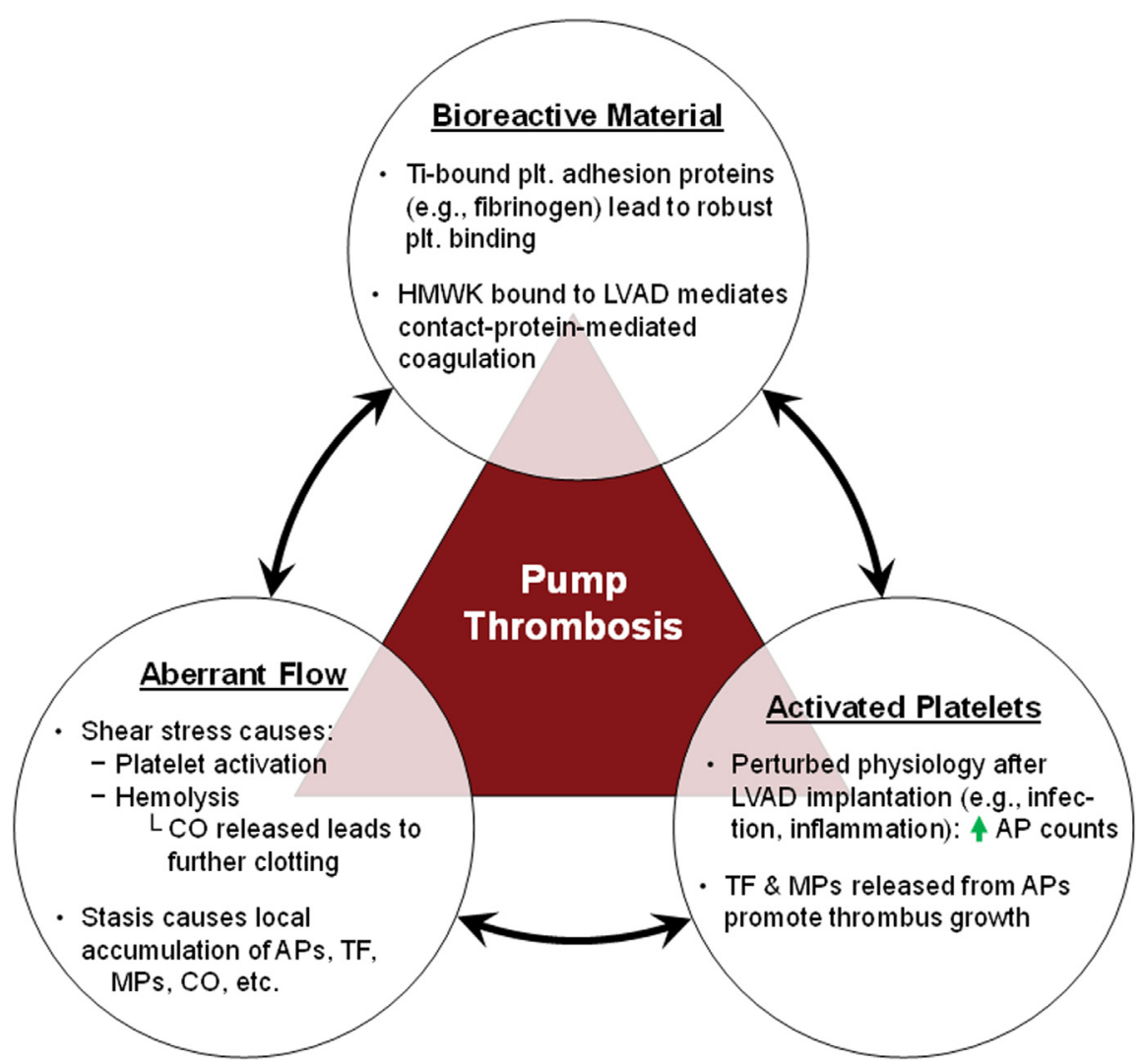

FIGURE 2. Virchow's triad of endothelial injury, hypercoagulability, and stasis serves as the conceptual framework for understanding the 3 fundamental determinants of pump thrombogenesis; that is, bioreactive material (ie, titanium), activated platelets, and aberrant flow. Ti, Titanium; plt., platelet; $H M W K$, high molecular weight kininogen; $L V A D$, left ventricular assist device; $A P$, activated platelet; $T F$, tissue factor; $M P$, microparticle; $C O$, carbon monoxide.

with negative-feedback mechanisms that normally initiate thrombolysis. For example, various contact proteins are now known to activate thrombin-activatable fibrinolysis inhibitor, which as its name implies, inhibits fibrin lysis and hence the dissolution of thrombi. ${ }^{15}$

Sintering (ie, forming a solid using heat and/or pressure without melting the material) can be used to mitigate some of titanium's thrombogenicity; this manufacturing process promotes the formation of a densely adherent pseudointima that hinders direct blood-metal interaction. As a result, sintered titanium may impede fibrinogen and HMWK adhesion. In fact, a recent study found sintering the inflow cannula of the HeartWare HVAD (HeartWare Inc, Framingham, Mass) led to a significant reduction in the incidence of pump thrombosis with that device. ${ }^{16}$

So, engineering best efforts notwithstanding and ignoring for a moment the myriad patient-level contributors to device thrombosis, current-generation LVADs exhibit a certain propensity to clot just based on the bioreactivity of the material from which they are made.

\section{Activated Platelets}

Virchow's second tenet posits that thrombogenesis preferentially occurs in hypercoagulable microenvironments.
Mechanical assist device implantation is thought to promote hypercoagulability for a host of reasons (eg, by inducing an inflammatory state, or as a result of infection). The common denominator among these processes is that each involves APs. ${ }^{17}$ The presence of supraphysiologic numbers of APs in patients with continuous-flow LVADs is well documented. ${ }^{18,19}$ As we saw earlier, APs form the foundations of pump thrombi and are considered to be the preeminent cell involved in device clotting. ${ }^{20}$ Consequently, perturbations in physiology after LVAD implantation that culminate in increased AP counts pose fundamental thrombogenic risks to patients.

Special mention should be given to 1 of these perturbators: infection. As reviewed by de Stoppelaar and colleagues, ${ }^{17}$ inflammatory and coagulation cascades triggered by infection invariably lead to platelet activation and the increased propensity for thrombosis in sepsis. Interestingly, this thrombogenic mechanism has manifested clinically: Preceding episodes of infection were identified in $38 \%$ of patients who had nonmechanical pump thrombi with the HeartMate II (Thoratec Corp, Pleasanton, Calif). ${ }^{21} \mathrm{~A}$ recent analysis of patients from the ADVANCE Bridge to Transplant trial and Continued Access Protocol found that, of those HeartWare patients 
TABLE 1. Possible clinical contributors to device thrombogenesis ${ }^{7}$

\begin{tabular}{l} 
Surgical \\
Inflow cannula \\
Malapposition \\
Angulation \\
Pump pocket depth (can affect inflow cannula apposition and/or \\
angulation) \\
Device management \\
Anticoagulation \\
Absent or shortened heparin bridge \\
Inadequate INR target \\
Too little time within therapeutic INR range \\
Antiplatelet \\
Insufficient ASA dosing \\
Bleeding \\
Destabilizes anticoagulation/antiplatelet therapy consistency \\
Thrombus detection \\
Biomarkers (eg, LDH and haptoglobin) \\
Insensitive \\
Actionable thresholds not standardized \\
Power spikes (unclear link to clotting) \\
\hline$I N R$, International normalized ratio; $A S A$, acetylsalicylic acid; $L D H$, lactate \\
dehydrogenase.
\end{tabular}

with sepsis, some $4 \%$ required device exchange secondary to pump thrombosis. ${ }^{22}$

Although APs may be the most important hematologic mediator of pump thrombogenesis, it is worth pointing out that device implantation can modulate other aspects of the procoagulant milieu. For instance, LVAD support has been demonstrated to increase thrombin activity, to induce hyperfibrinogenemia, and to independently promote $\mathrm{TF}$ generation. ${ }^{13,23}$ Although TF production is believed to be largely platelet-mediated, there is now intriguing evidence that suggests mechanical circulatory support results in sustained endothelial dysfunction and that this damaged endothelium contributes some of the $\mathrm{TF}$ observed in patients with LVADs. ${ }^{23}$

Clearly, APs are a fundamental requirement for device thrombogenesis, acting as a common end-effector for numerous processes occurring in the hypercoagulable state that is LVAD implantation. The phenomenon overwhelmingly responsible for activating these platelets, however, arises from the third component of our modified Virchow's triad: aberrant flow.

\footnotetext{
Aberrant Flow

An advanced engineering degree is not requisite for appreciating the significant influence that aberrant blood flow has on clot development. Some terminology is required, however (see Figure 3). We will consider "aberrant" flow to be any blood flow that generates high shear stress or that is stagnant.

The original Achilles' heel of continuous-flow LVADs was high shear stress. With iterative improvements the
}

amount of shear produced by continuous-flow devices has lessened. ${ }^{24,25}$ Although more manageable in the newest LVADs, the shearing found in these devices still has thrombogenic consequences-in particular, due to SIPA and, to a lesser extent, because of hemolysis.

We learned earlier that APs are central to pump thrombogenesis; it is now well established that the primary mechanism responsible for activating these platelets is shear stress (see Figure 1). ${ }^{26-28}$ As reviewed by Jackson and colleagues, ${ }^{29}$ extensive in vitro and in vivo studies have identified a continuum of at least 3 modes of SIPA, all of which ultimately trigger platelet activation via adhesion-induced molecular pathways. ${ }^{29}$ At low to intermediate levels of shear, SIPA is mainly facilitated by integrin $\alpha_{\mathrm{IIb}} \beta_{3}$, a platelet membrane protein that can engage fibrinogen adsorbed on various surfaces. ${ }^{29}$ At higher shear, SIPA becomes increasingly vWF-dependent (here, vWF adsorbed to titanium binds its complementary receptor on platelets, GP1b); in settings of pathologically high shear, SIPA is exclusively mediated by adhesive bonds between vWF and GP1b. ${ }^{29}$ Our understanding of platelet activation in these high-shear states was recently expanded when a group identified a specific gene, SVIL (encoding the platelet protein supervillin), which seems to influence high-shearstress thrombus formation. ${ }^{30}$

We must point out that the vWF-dependent end of the SIPA spectrum and its resultant effects on pump clotting stand in contrast to the well-publicized phenomenon of LVAD-induced acquired vWF syndrome (wherein bleeding results from degradation of large $\mathrm{vWF}$ multimers) ${ }^{31}$; further research is necessary to reconcile the relative weight of these competing issues. Perhaps counterintuitively, blood loss (secondary to this syndrome, for example) can encourage thrombogenesis if adherence to anticoagulation and/or antiplatelet therapy becomes destabilized in response to a bleeding episode. ${ }^{32}$

In addition to being dependent on the intensity of the shear stress, we now know that SIPA is also a function of the duration of the shear exposure. ${ }^{27,33}$ Because the shear conditions in continuous-flow LVADs are dynamic - both in terms of intensity and duration-SIPA has ample opportunity to occur in the setting of such support. For example, cannula positioning can radically alter the quality of flow within both the left ventricle and device (inflow location) and of the flow entering the aorta (outflow cannulation). ${ }^{34,35}$ In their examination of clotting in the HeartMate II, Uriel and colleagues ${ }^{21}$ attributed all 5 mechanically induced thromboses in their series to either abnormal inflow cannula positioning or to deformed outflow grafts. Certain cannula configurations may thus be especially vulnerable to thrombogenesis if they result in turbulent-flow-induced shear stresses sufficient for SIPA. Yet, shear stress may affect platelets beyond simple activation as emerging evidence implies a role for shear 

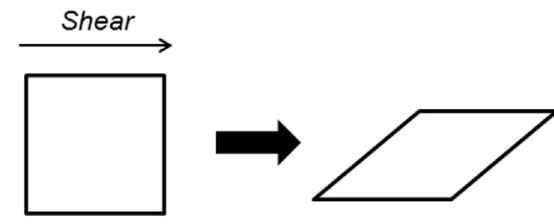

A

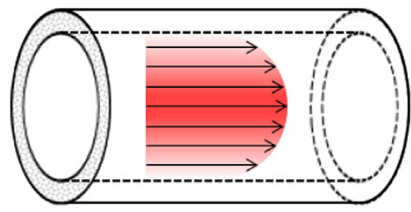

C

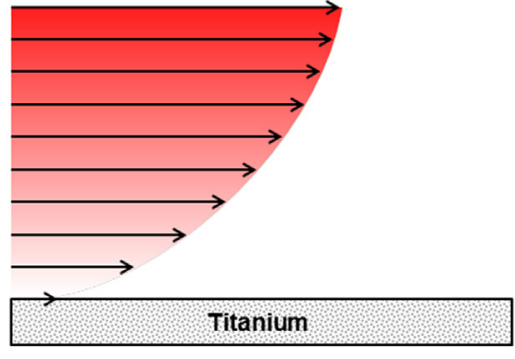

D

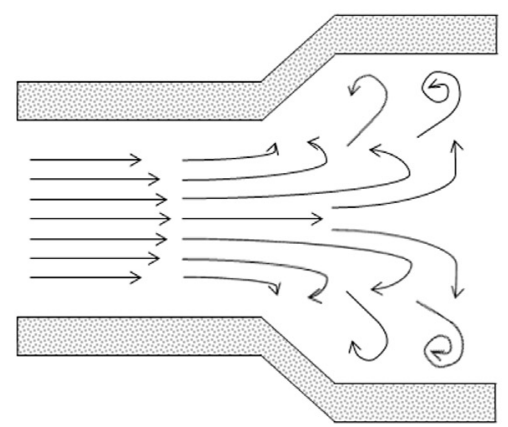

FIGURE 3. Shear (or shear stress) is a stress (a force per unit area) that acts parallel to the surface of an object (solid or fluid). A, Visual representation of a shear (thin arrow) acting on a solid (the square), deforming it into a rhombus. B, Blood flowing along a titanium surface is exposed to a shear such that the blood velocity (arrows) is 0 immediately atop the titanium, increasing as the distance from the surface increases. Fluid (eg, blood) flow can be either laminar or turbulent. C, Laminar flow is simply flow that is streamline. D, Turbulent flow is disorderly, having tumbling cross-currents and swirls.

stress in the production of prothrombotic, platelet-derived MPs as well. ${ }^{36}$

High shear stresses can additionally contribute to thrombogenesis through hemolysis. It is traditionally held that high shear stress is damaging to red blood cells and that shear can thereby cause a hemolytic anemia. Hemolysis may further occur in LVADs when erythrocytes are exposed to excessive shear arising from in situ thrombi, as illustrated in Figure $1 .{ }^{37}$ New research demonstrates that hemolysis resulting from high shear can precipitate thrombus formation when heme released by lysed red blood cells is catabolized to carbon monoxide, which has been implicated to enhance clot strength and the velocity of thrombus growth, to promote hyperfibrinogenemia, and to impair fibrinolysis. ${ }^{38,39}$

TABLE 2. Evolving science: Areas of research for improving left ventricular assist device (LVAD) thromboresistance

\section{Materials science}

Examining role of Ti-induced hypersensitivity in thrombogenesis ${ }^{42}$

Developing novel drug coatings (eg, argatroban, nitric oxide) ${ }^{43}$

Incorporating Ti surface treatments (eg, sintering) into device design

Coagulation and platelet pharmacology

New drug development: HMWK and TAFI inhibition ${ }^{44,45}$

Determining the role of newer platelet antagonists (eg, thienopyridines and GPIIb/IIIA inhibitors) in LVAD support ${ }^{46,47}$

LVAD hemorheology

Generating computational models to predict thrombogenicity $8,48,49$

$\overline{T i \text {, Titanium; } H M W K \text {, high molecular weight kininogen; TAFI, thrombin-activatable }}$ fibrinolysis inhibitor; $L V A D$, left ventricular assist device.
The aforementioned topic of cannula positioning exemplifies another key element in aberrant-flow-generated thrombosis: stasis. True, some cannulation schemes might be susceptible to turbulence and high shear but others may predispose to stagnant flow that itself can stimulate thrombogenesis. Flow phenomena that reduce blood washout and increase dwell time (stasis being the most extreme example of this) lead to the local accumulation of the very effectors and substrates-eg, APs, MPs, TF, contact proteins-vital for thrombogenesis. ${ }^{20,40}$ The dangers of these resultant concentration increases are highlighted by the recent case of an LVAD-supported patient who succumbed to an embolized intraventricular thrombus that was attributed to flow stasis. ${ }^{41}$

\section{FUTURE TECHNOLOGIC IMPLICATIONS}

The remarkable rate at which LVAD technology is evolving hinges on the continued, unrelenting efforts of physicians, engineers, and basic scientists alike. The future implications of this work-some of which are listed in Table 2-are exciting. New surface treatments for titanium, the rational development of novel anticoagulants, and powerful computational fluid dynamic modeling are just a few of the research areas with the potential to help us further decrease LVAD thrombogenicity. Such innovations will surely provide forthcoming LVADs with safety profiles even better than those of current durable, continuous-flow devices. Moreover, they underscore the importance of 
trying to understand complex phenomena like pump thrombi on their most fundamental levels.

Nevertheless, technologic questions remain. Notably, what influence pump design (axial-flow vs centrifugal) has on clotting proclivity is still unclear. Moving forward, we will have to synergize our improved understanding (and resultant advancements) with contemporaneous clinical insights, like those into patient-specific clotting risk factors and thrombus detection.

\section{References}

1. Kirklin JK, Naftel DC, Pagani FD, Kormos RL, Stevenson LW, Blume ED, et al. Sixth INTERMACS annual report: a 10,000-patient database. J Heart Lung Transplant. 2014;33:555-64.

2. Starling RC, Moazami N, Silvestry SC, Ewald G, Rogers JG, Milano CA, et al. Unexpected abrupt increase in left ventricular assist device thrombosis. $N$ Engl J Med. 2014;370:33-40.

3. Kirklin JK, Naftel DC, Kormos RL, Pagani FD, Myers SL, Stevenson LW, et al. Interagency Registry for Mechanically Assisted Circulatory Support (INTERMACS) analysis of pump thrombosis in the HeartMate II left ventricular assist device. J Heart Lung Transplant. 2014;33:12-22.

4. Najjar SS, Slaughter MS, Pagani FD, Starling RC, McGee EC, Eckman P, et al. An analysis of pump thrombus events in patients in the HeartWare ADVANCE bridge to transplant and continued access protocol trial. J Heart Lung Transplant. 2014:33:23-34.

5. Boyle AJ, Jorde UP, Sun B, Park SJ, Milano CA, Frazier OH, et al. Pre-operative risk factors of bleeding and stroke during left ventricular assist device support: an analysis of more than 900 HeartMate II outpatients. J Am Coll Cardiol. 2014;63: 880-8.

6. Birschmann I, Dittrich M, Eller T, Wiegmann B, Reininger AJ, Budde U, et al. Ambient hemolysis and activation of coagulation is different between HeartMate II and HeartWare left ventricular assist devices. J Heart Lung Transplant. 2014; 33:80-7.

7. Mehra MR, Stewart GC, Uber PA. The vexing problem of thrombosis in long-term mechanical circulatory support. J Heart Lung Transplant. 2014;33: $1-11$.

8. Bluestein D, Girdhar G, Einav S, Slepian MJ. Device thrombogenicity emulation: a novel methodology for optimizing the thromboresistance of cardiovascular devices. J Biomech. 2013;46:338-44.

9. Saba HI, Roberts HR. Hemostasis and thrombosis: Practical guidelines in clinical management. Chichester, West Sussex: John Wiley \& Sons, Inc; 2014.

10. Morel O, Morel N, Jesel L, Freyssinet JM, Toti F. Microparticles: a critical component in the nexus between inflammation, immunity, and thrombosis. Semin Immunopathol. 2011;33:469-86.

11. Diehl P, Aleker M, Helbing T, Sossong V, Beyersdorf F, Olschewski M, et al. Enhanced microparticles in ventricular assist device patients predict platelet, leukocyte and endothelial cell activation. Interact Cardiovasc Thorac Surg. 2010;11:133-7.

12. Tanaka K. Recent Advances in Thrombosis and Hemostasis 2008. Tokyo, Japan: Springer; 2008. Available at: http://link.springer.com/chapter/10.1007/978-4431-78847-8_1\#. Accessed July 30, 2014.

13. Nielsen VG, Kirklin JK, Holman WL, Steenwyk BL, George JF, Zhou F, et al. Mechanical circulatory device thrombosis: a new paradigm linking hypercoagulation and hypofibrinolysis. ASAIO J. 2008;54:351-8.

14. Mikhalovska LI, Santin M, Denyer SP, Lloyd AW, Teer DG, Field S, et al. Fibrinogen adsorption and platelet adhesion to metal and carbon coatings. Thromb Haemost. 2004;92:1032-9.

15. Nielsen VG, Steenwyk BL, Gurley WQ. Contact activation prolongs clot lysis time in human plasma: role of thrombin-activatable fibrinolysis inhibitor and Factor XIII. J Heart Lung Transplant. 2006;25:1247-52.

16. Soltani S, Kaufmann F, Vierecke J, Kretzschmar A, Hennig E, Stein J, et al. Design changes in continuous-flow left ventricular assist devices and lifethreatening pump malfunctions. Eur J Cardiothorac Surg. September 10, 2014 [Epub ahead of print].

17. de Stoppelaar SF, van 't Veer C, van der Poll T. The role of platelets in sepsis. Thromb Haemost. 2014;112:666-77.
18. Radovancevic R, Matijevic N, Bracey AW, Radovancevic B, Elayda M, Gregoric ID, et al. Increased leukocyte-platelet interactions during circulatory support with left ventricular assist devices. ASAIO J. 2009;55: 459-64.

19. Bonaros N, Mueller MR, Salat A, Schima H, Roethy W, Kocher AA, et al. Extensive coagulation monitoring in patients after implantation of the MicroMed Debakey continuous flow axial pump. ASAIO J. 2004;50:424-31.

20. Bluestein D. Research approaches for studying flow-induced thromboembolic complications in blood recirculating devices. Expert Rev Med Devices. 2004;1: $65-80$.

21. Uriel N, Han J, Morrison KA, Nahumi N, Yuzefpolskaya M, Garan AR, et al. Device thrombosis in HeartMate II continuous-flow left ventricular assist devices: a multifactorial phenomenon. J Heart Lung Transplant. 2014;33: 51-9.

22. John R, Aaronson KD, Pae WE, Acker MA, Hathaway DR, Najarian KB, et al. Drive-line infections and sepsis in patients receiving the HVAD system as a left ventricular assist device. J Heart Lung Transplant. 2014;33: 1066-73.

23. John R, Lee $\mathrm{S}$. The biological basis of thrombosis and bleeding in patients with ventricular assist devices. J Cardiovasc Transl Res. 2009;2:63-70.

24. Fraser KH, Zhang T, Taskin ME, Griffith BP, Wu ZJ. A quantitative comparison of mechanical blood damage parameters in rotary ventricular assist devices: shear stress, exposure time and hemolysis index. J Biomech Eng. 2012;134: 081002.

25. Moazami N, Fukamachi K, Kobayashi M, Smedira NG, Hoercher KJ, Massiello A, et al. Axial and centrifugal continuous-flow rotary pumps: a translation from pump mechanics to clinical practice. J Heart Lung Transplant. 2013; 32:1-11.

26. Nesbitt WS, Westein E, Tovar-Lopez FJ, Tolouei E, Mitchell A, Fu J, et al. A shear gradient-dependent platelet aggregation mechanism drives thrombus formation. Nat Med. 2009;15:665-73.

27. Zhang JN, Bergeron AL, Yu Q, Sun C, McBride L, Bray PF, et al. Duration of exposure to high fluid shear stress is critical in shear-induced platelet activation-aggregation. Thromb Haemost. 2003;90:672-8.

28. Holme PA, Orvim U, Hamers MJ, Solum NO, Brosstad FR, Barstad RM, et al. Shear-induced platelet activation and platelet microparticle formation at blood flow conditions as in arteries with a severe stenosis. Arterioscler Thromb Vasc Biol. 1997; 17:646-53.

29. Jackson SP, Nesbitt WS, Westein E. Dynamics of platelet thrombus formation. J Thromb Haemost. 2009;7(Suppl 1):17-20.

30. Edelstein LC, Luna EJ, Gibson IB, Bray M, Jin Y, Kondkar A, et al. Human genome-wide association and mouse knockout approaches identify platelet supervillin as an inhibitor of thrombus formation under shear stress. Circulation. 2012;125:2762-71.

31. Meyer AL, Malehsa D, Bara C, Budde U, Slaughter MS, Haverich A, et al. Acquired von Willebrand syndrome in patients with an axial flow left ventricular assist device. Circ Heart Fail. 2010;3:675-81.

32. Stulak JM, Lee D, Haft JW, Romano MA, Cowger JA, Park SJ, et al. Gastrointestinal bleeding and subsequent risk of thromboembolic events during support with a left ventricular assist device. J Heart Lung Transplant. 2014;33:60-4

33. Sheriff J, Soares JS, Xenos M, Jesty J, Slepian MJ, Bluestein D. Evaluation of shear-induced platelet activation models under constant and dynamic shear stress loading conditions relevant to devices. Ann Biomed Eng. 2013;41:1279-96.

34. Karmonik C, Partovi S, Loebe M, Schmack B, Weymann A, Lumsden AB, et al. Computational fluid dynamics in patients with continuous-flow left ventricular assist device support show hemodynamic alterations in the ascending aorta. J Thorac Cardiovasc Surg. 2014;147:1326-33.e1.

35. Yang N, Deutsch S, Paterson EG, Manning KB. Numerical study of blood flow at the end-to-side anastomosis of a left ventricular assist device for adult patients. J Biomech Eng. 2009;131:111005.

36. Nascimbene A, Hernandez R, George JK, Parker A, Bergeron AL, Pradhan S, et al. Association between cell-derived microparticles and adverse events in patients with nonpulsatile left ventricular assist devices. J Heart Lung Transplant. 2014;33:470-7.

37. Ravichandran AK, Parker J, Novak E, Joseph SM, Schilling JD, Ewald GA, et al. Hemolysis in left ventricular assist device: a retrospective analysis of outcomes. J Heart Lung Transplant. 2014;33:44-50.

38. Nielsen VG, Pearson EC, Smith MC. Increased carbon monoxide production by hemeoxygenase-1 caused by device-mediated hemolysis: thrombotic phantom menace? Artif Organs. 2013;37:1008-14. 
39. Smith MC, Nielsen VG. Detection of carboxyhemefibrinogen and methemefibrinogen in a patient with thrombosis of a HeartMate II ventricular assist device. ASAIO J. 2013;59:93-5.

40. Wong K, Samaroo G, Ling I, Dembitsky W, Adamson R, del Álamo JC, et al. Intraventricular flow patterns and stasis in the LVAD-assisted heart. $J$ Biomech. 2014;47:1485-94.

41. May-Newman K, Wong YK, Adamson R, Hoagland P, Vu V, Dembitsky W. Thromboembolism is linked to intraventricular flow stasis in a patient supported with a left ventricle assist device. ASAIO J. 2013; 59:452-5.

42. Kounis NG, Soufras GD, Davlouros P, Tsigkas G, Hahalis G. Thrombus Formation Patterns in HeartMate II continuous-flow left ventricular assist devices: a multifactorial phenomenon involving Kounis syndrome? ASAIO J. April 10, 2014 [Epub ahead of print].

43. Major TC, Brisbois EJ, Jones AM, Zanetti ME, Annich GM, Bartlett RH, et al. The effect of a polyurethane coating incorporating both a thrombin inhibitor and nitric oxide on hemocompatibility in extracorporeal circulation. Biomaterials. 2014;35:7271-85
44. Kenniston JA, Faucette RR, Martik D, Comeau SR, Lindberg AP, Kopacz KJ et al. Inhibition of plasma kallikrein by a highly specific, active site blocking antibody. J Biol Chem. 2014;289:23596-608.

45. Foley JH, Kim PY, Mutch NJ, Gils A. Insights into thrombin activatable fibrinolysis inhibitor function and regulation. J Thromb Haemost. 2013;11(Suppl 1) 306-15.

46. Dalén M, Sartipy U, Corbascio M, Lund LH, Grinnemo KH. Non-responders to antiplatelet therapy in patients with left ventricular assist devices. J Heart Lung Transplant. 2013;32(Suppl 1):S174.

47. Bellumkonda L, Subrahmanyan L, Jacoby D, Bonde P. Left ventricular assist device pump thrombosis: is there a role for glycoprotein IIb/IIIa inhibitors? ASAIO J. 2014;60:134-6.

48. Chiu WC, Slepian MJ, Bluestein D. Thrombus formation patterns in the HeartMate II ventricular assist device: clinical observations can be predicted by numerical simulations. ASAIO J. 2014;60:237-40.

49. Fraser KH, Taskin ME, Griffith BP, Wu ZJ. The use of computational fluid dynamics in the development of ventricular assist devices. Med Eng Phys 2011;33:263-80.

\title{
EDITORIAL COMMENTARY
}

\section{Left ventricular assist device pump thrombosis: Understanding mechanisms as a key to causality}

\author{
Robert L. Kormos, MD
}

See related article on pages 667-73.

To understand left ventricular assist device (LVAD) reliability, one must incorporate the concepts not only of mechanical reliability but also of biologic reliability. Biologic reliability combines the constraints of both design and manufacturing with the performance of the device within the biologic environment, in this case the patient with end-stage congestive heart failure. Thus not only is the design of an LVAD with its biomaterial interactions crucial to the understanding of causality for pump-related thrombosis, but the patient-related inflammatory milieu of end-stage heart failure must also be considered, along with the variability in clinical management practices.

In this issue of the Journal, De Biasi and colleagues, representing expertise in cardiothoracic surgery and

\footnotetext{
From the Department of Cardiothoracic Surgery, University of Pittsburgh, Pittsburgh, $\mathrm{Pa}$.

Disclosures: Author has nothing to disclose with regard to commercial support.

Received for publication Nov 23, 2014; accepted for publication Nov 24, 2014; available ahead of print Jan 9, 2015

Address for reprints: Robert L. Kormos, MD, Department of Cardiothoracic Surgery, University of Pittsburgh, Presbyterian University Hospital, 200 Lothrop St, Suite C700, Pittsburgh, PA 15213 (E-mail: kormosrl@upmc.edu).

J Thorac Cardiovasc Surg 2015;149:673-4

$0022-5223 / \$ 36.00$

Copyright () 2015 by The American Association for Thoracic Surgery

http://dx.doi.org/10.1016/j.jtcvs.2014.11.073
}

biomedical engineering, have proposed that LVAD pumprelated thrombosis is a result of many factors, best summarized by the principles espoused by Virchow more than a century ago ${ }^{1}$ to explain the risk of development of venous thrombosis and pulmonary embolism. De Biasi and colleagues have cleverly drawn on this construct to summarize Virchow's principles of endothelial injury, hypercoagulability, and stasis and translate that triad into device biomaterial interactions, platelet activation and aberrant flow patterns within the pump and its cannulas. De Biasi and colleagues were stimulated to address pump thrombosis according to this scientific approach by recent articles that have identified this adverse event as a problem with a rising prevalence for the HeartMate II axial-flow rotary LVAD (Thoratec Corporation, Pleasanton, Calif). But, as De Biasi and colleagues note, this problem is not exclusive to the axialflow pumps but is also seen in the HeartWare centrifugal LVAD (HeartWare Inc, Framingham, Mass). In either case, pump thrombosis often results in the need for pump exchange, which carries its own risks of morbidity and mortality, or the need for systemic thrombolytic therapy, which with repeated use may also increase the incidence of hemorrhagic cerebral vascular events.

In a healthy individual without an implant, a balance is maintained between the coagulation and fibrinolytic systems to prevent severe blood loss during vessel puncture while also reestablishing normal blood flow to the vessel after repair. When artificial surfaces are introduced, 